\title{
Educação em direitos humanos e letramento digital: uma proposta de formação para a cidadania
}

- Educación en derechos humanos y alfabetización digital: una propuesta de formación para la ciudadanía

- Education in human rights and digital literacy: a training proposal for citizenship

Mara Juliane Woiciechoski Helfenstein ${ }^{1}$

Matheus Trindade Velasques ${ }^{2}$

Resumo: Este artigo tem como objetivo apresentar a proposta pedagógica e as ações desenvolvidas, no ano de 2020, pelo projeto de educação em direitos humanos e mídias digitais "Produção audiovisual, linguagens e humanidades" no Instituto Federal Catarinense, Campus Avançado Sombrio (IFC-CAS). No Plano Nacional de Educação em Direitos Humanos (PNEDH) salienta-se que educar em direitos humanos envolve a apreensão de conhecimentos historicamente construídos, a afirmação de valores e práticas pedagógicas participativas e ativas voltadas para a cultura dos direitos humanos a fim de contribuir na formação cidadã. Atividades de ensino e pesquisa asso-

1 Doutorado em Filosofia. Professora do Instituto Federal Catarinense, Campus Avançado Sombrio. Coordenadora do Projeto de ações integradas e educação em direitos humanos "Produção audiovisual, Linguagens e Humanidades". mara.helfenstein@ifc.edu.br

2 Mestrado em Letras. Professor do Instituto Federal Catarinense, Campus Avançado Sombrio. Coordenador Adjunto do Projeto de ações integradas e educação em direitos humanos "Produção audiovisual, Linguagens e Humanidades".matheus.velasques@iff.edu.br 
ciadas ao letramento digital apresentam-se como uma estratégia metodológica participativa e ativa em educação, pois possibilitam ao aluno assumir o papel de sujeito no processo de construção de conhecimento. Este artigo foi produzido a partir de estudos de bibliografia especializada em educação em direitos humanos e da contribuição dos Estudos Culturais em Educação para discussões sobre mídias e letramento digital, e apresenta o relato das ações desenvolvidas pelo projeto com discentes das três turmas de primeiros anos do ensino técnico integrado ao ensino médio da instituição, assim como uma análise dos resultados alcançados.

Palavras-chave: Educação em direitos humanos. Letramento digital. Formação para a cidadania.

Resumen: Este artículo tiene como objetivo presentar la propuesta pedagógica y las acciones desarrolladas en 2020 por el proyecto de educación en derechos humanos y medios digitales "Producción audiovisual, lenguajes y humanidades" en el Instituto Federal Catarinense, Campus Avanzado de Sombrio (IFC-CAS). En el Plan Nacional de Educación en Derechos Humanos (PNE$\mathrm{DH}$ ) se enfatiza que la educación en derechos humanos implica la aprehensión de saberes históricamente construidos, la afirmación de valores y prácticas pedagógicas participativas y activas orientadas a la cultura de los derechos humanos para contribuir a la educación ciudadana. Las actividades de docencia e investigación asociadas a la alfabetización digital se presentan como una estrategia metodológica participativa y activa en la educación, ya que permiten al alumno asumir el rol de sujeto en el proceso de construcción del conocimiento. Este artículo fue elaborado a partir de estudios de bibliografía especializada en educación en derechos humanos y la contribución de los Estudios Culturales en Educación a las discusiones sobre alfabetización mediática y digital, y presenta un relato de las acciones desarrolladas por el proyecto con estudiantes de las tres clases de primer año de la educación técnica integrada a la educación secundaria de la institución, así como un análisis de los resultados alcanzados.

Palabras clave: Educación en derechos humanos. Alfabetización digital. Formación para la ciudadanía.

Abstract: This article aims at presenting the pedagogical proposal and the actions developed in 2020 by the human rights and digital media education 
project "Audiovisual production, languages and humanities" at the Federal Institute of Catarinense, Sombrio Advanced Campus (IFC-CAS). In the National Plan for Human Rights Education (PNEDH) it is emphasized that human rights education involves the apprehension of historically constructed knowledge, the affirmation of values and active pedagogical participative practices aimed at the culture of human rights in order to contribute to citizen education. Teaching and research activities associated with digital literacy are presented as a participatory and active methodological strategy in education, as they enable the student to assume the role of subject in the knowledge construction process. This article was written based on studies of specialized bibliography in human rights education and the contribution of Cultural Studies in Education to discussions on media and digital literacy, as well as presents the report of the actions developed by the project with students from the three first-year classes of the technical education integrated with the institution's secondary education, as well as an analysis of the results achieved.

Keywords: Human rights education. Digital literacy. Training for citizenship.

\section{Introdução}

Em uma sociedade marcada por contradições e desigualdades como a brasileira, a educação, enquanto direito humano, viabiliza o acesso a outros direitos, fundamentais ganha ainda mais importância. Tendo o acesso à educação assegurado, ainda é preciso pensar como a educação formal contribuirá para que o ser em formação tenha condições de reconhecer-se enquanto sujeito de direitos e deveres, enquanto cidadão capaz de atuação e capaz de reconhecer nos outros a mesma dignidade humana que deve reconhecer em si. Essa problemática integra a discussão contemporânea acerca da formação para o exercício da cidadania e a formação humana baseada na cultura de respeito e valorização dos direitos humanos, apresentada na concepção de educação em direitos humanos.

A educação em direitos humanos refere-se ao "uso de concepções e práticas educativas fundadas nos Direitos Humanos e em seus processos de promoção, proteção, defesa e aplicação na vida cotidiana e cidadã de sujeitos de direitos e de responsabilidades individuais e coletivas" (BRASIL, 2012). Como abarcam uma grande gama de temas e questões, tanto teóricas quanto práticas (relacionadas às experiências vividas em comunidade), as ações educativas permitem uma abordagem interdisciplinar e transversal, contribuindo para a integração de 
saberes e compartilhamento de práticas em uma instituição de educação.

Quando se pensa em uma proposta de educação em direitos humanos, alguns desafios se apresentam aos atores que pretendem colocá-la em prática (BRASIL, 2012). Um dos desafios impostos à instituição educacional se refere ao reconhecimento político das diversidades, na medida em que se faz necessário um ambiente que respeite as diversidades e combata situações de preconceitos e discriminações. Essa questão implica na constituição de uma política voltada para a inclusão e para a participação de representantes dos diversos segmentos que integram a comunidade em todos os espaços. Quanto às ações educativas e a construção de conhecimento, um importante desafio se refere à necessidade de considerar o protagonismo discente, favorecendo a sua participação ativa, o que implica a reflexão sobre as práticas pedagógicas. Ainda, dentre as preocupações de quem desenvolve ações de educação em direitos humanos na educação básica, figuram entre as mais prementes aquelas relacionadas a distorções de episódios da história, descrédito da ciência e normalização da violência. Esses discursos podem ser mapeados em enunciados presentes em diferentes setores da sociedade - produzidos, inclusive, por autoridades governamentais - os quais chegam, inevitavelmente, nas salas de aula por meio de diferentes sujeitos. Considerando o papel preponderante que as mídias digitais têm nesse processo, bem como seu potencial de disseminação de informações, optou-se por propor metodologicamente a produção de um formato de mídia digital - nesse caso, o de vídeos - acerca das temáticas discutidas em sala de aula a respeito de violações de direitos humanos como forma de produção final de um percurso de problematizações, debates, pesquisa e formação sobre o tema.

Ademais, é importante salientar que a proposta de uso da mídia audiovisual no projeto foi construída com base nas discussões realizadas pelo pesquisador britânico David Buckingham acerca do uso das tecnologias no contexto escolar, as quais emergem a partir do ethos contingente da área de pesquisa denominada Estudos Culturais em Educação. Buckingham (2015) defende que é papel da escola propor um letramento digital que não apenas torne o estudante em um usuário instrumental de tecnologias digitais, dominando o uso de ferramentas como planilhas e editores de texto, ou ainda tornando-o um classificador de informações da web como verdadeiras ou falsas.

O presente artigo tem como principal objetivo apresentar as ações desenvolvidas no ano de 2020 pelo projeto de ações integradas "Produção audiovisual, linguagens e Humanidades: projeto de educação em direitos humanos"3 no Instituto Federal Catarinense, Campus Avançado Sombrio, e dis-

3 O desenvolvimento do projeto contou com apoio financeiro do Instituto Federal Catarinense - IFC. 
cutir seus principais resultados. O projeto integra ações de ensino, pesquisa e extensão, voltadas para a promoção do debate, construção e compartilhamento de conhecimentos sobre direitos humanos, visando contribuir para a formação integral do ser humano e para o exercício da cidadania. $O$ ano de 2020 foi marcado pelo início da pandemia de COVID-19, impondo a necessidade de adaptações das atividades educacionais em todas as dimensões para realização exclusivamente em formato de estudos remotos. Além da exposição das ações realizadas, busca-se fazer uma análise crítica dessas ações à luz do aporte teórico de bibliografia especializada em educação em direitos humanos e das contribuições dos Estudos Culturais em Educação para as discussões acerca do uso de tecnologias na escola.

\section{Educação em direitos humanos e formação para a cidadania}

A formação para o exercício da cidadania se apresenta como um dos objetivos centrais da educação formal no Brasil desde a redemocratização marcada pela promulgação da Constituição Federal de 1988 (Art. 205), uma vez que é reconhecida como condição fundamental para a sustentação de um Estado democrático (Art.1 ${ }^{\circ}$ ). Da mesma forma, a construção de uma sociedade democrática, que se dá no contexto histórico, na dimensão da participação efetiva dos processos de decisão que definem os rumos da sociedade nas mais variadas áreas da vida coletiva (BRASIL, 1997), só é possível com o efetivo exercício da cidadania. Na Declaração Universal dos Direitos Humanos (DUDH) de 1948, da qual o Brasil é signatário, a educação é compreendida como um direito (Art. XXVI) e como um meio indispensável para a promoção, acesso e realização de outros direitos. Tal finalidade da educação se apresenta também na Lei de Diretrizes e Bases da Educação Nacional (LDB), Artigos $2^{\circ} \mathrm{e}$ 3० (BRASIL, 1996), e em outros documentos normativos das políticas educacionais que, em última instância, estão vinculadas a estas.

Educar para o exercício da cidadania implica em formar sujeitos capazes de compreendê-la como "participação social e política, assim como exercício de direitos e deveres políticos, civis e sociais [...], respeitando o outro e exigindo para si o mesmo respeito." (BRASIL, 1997, p. 9) Em outras palavras, educar para a cidadania pressupõe uma prática pedagógica que proporcione o acesso aos conhecimentos historicamente construídos, lutas e conquistas relativas aos direitos e deveres, mas que se volte, também, para a compreensão e reflexão da realidade social em que os educandos estejam inseridos e implicados. Esse movimento deve possibilitar que se reconheçam enquanto sujeitos de direitos e deveres, e desenvolvam capacidades necessárias para a participação social e política efetiva, isto é, que sejam capazes de exercerem os direitos conquis- 
tados, assim como participarem da ampliação e criação de direitos, o que se caracteriza como cidadania ativa (BENEVIDES, 1994; BRASIL, 2009, 2012).

É importante notar o estreito vínculo entre democracia, direitos humanos e cidadania, como destaca Norberto Bobbio em sua obra A era dos direitos (2004). A democracia, enquanto sistema político, fundamenta-se nos ideais de liberdade e igualdade de todos perante a lei, e o reconhecimento dos direitos humanos são a base das constituições democráticas. Factualmente, a democracia se sustenta no exercício da liberdade e participação dos indivíduos, no compromisso com a garantia efetiva dos seus direitos fundamentais, de modo a promover condições para o exercício da cidadania, a tolerância e a cultura da não violência.

[...] sem direitos do homem reconhecidos e protegidos, não há democracia; sem democracia, não existem as condições mínimas para a solução pacífica dos conflitos. Em outras palavras, a democracia é a sociedade dos cidadãos, e os súditos se tornam cidadãos quando thes são reconhecidos alguns direitos fundamentais. (BOBBIO, 2004, p. 6)

Nesse sentido, a democracia é considerada o regime político que apresenta as condições que mais favorecem o exercício da cidadania, a promoção e a efetividade dos direitos humanos. Nesse contexto, a educação em direitos humanos se apresenta como concepção fundamental no processo de formação para o exercício da cidadania, na medida em que abarca um conjunto de conhecimentos e princípios voltados para formação humana para viver de acordo com uma cultura democrática, pautada nos "valores da tolerância, da solidariedade, da justiça social e na sustentabilidade, na inclusão e na pluralidade." (BRASIL, 2009, p.24).

A elaboração dos Parâmetros Curriculares Nacionais para o Ensino Básico (PCN), em 1997, representa um marco na instituição de políticas públicas voltadas para a educação em direitos humanos no Brasil, pois apresentam diretrizes para o processo de ensino-aprendizagem dos temas transversais, todos voltados à formação para a cidadania (BRASIL, 1997). Logo após, tem-se o lançamento do Plano Nacional de Educação em Direitos Humanos (PNEDH) em 2003, revisto em 2006, pautado em diretrizes de documentos internacionais resultantes de conferências sobre educação promovidas pela ONU, e as Diretrizes Nacionais para a Educação em Direitos Humanos de 2012.

No PNEDH (BRASIL, 2009, p. 25) se apresenta a seguinte concepção de educação em direitos humanos:

[...] um processo sistemático e multidimensional que orienta a formação do sujeito de direito articulando as dimensões de apreensão de conhecimentos historicamente construídos sobre direitos humanos; a afirmação de valores, atitudes e práticas sociais que expressem a cultura dos direitos humanos; a formação de uma consciên- 
cia cidadã capaz de se fazer presente nos níveis cognitivos, sociais, éticos e políticos; o desenvolvimento de processos metodológicos participativos e de construção coletiva; o fortalecimento de práticas individuais e sociais geradoras de ações e instrumentos a favor da promoção, da proteção e da defesa dos direitos humanos, assim como da reparação de suas violações.

Essa concepção de educação, estreitamente vinculada à formação para a cidadania ativa, mostra estar dirigida para três dimensões principais (BRASIL, 2009), que são descritas como: a) conhecimentos e habilidades; b) valores, atitudes e comportamentos; c) ação. Pode-se interpretar essas três dimensões como: 1) histórico-social: o conhecimento, no sentido de compreender os direitos humanos em sua trajetória histórica e contexto atual, e em como isso diz respeito a cada um e todos; 2) ética-moral: estimular a reflexão ética acerca de valores, ações e comportamentos no que tange os direitos humanos, a fim de fortalecê-los; 3) ação ética-política: promover a ação e o engajamento por meio de atividades na promoção e defesa dos direitos humanos e na reparação de violações. Essas três dimensões também se alinham com o tripé apresentado por Candau e Sacavino $(2013$, p. 61) ao exporem as teses sobre educação em direitos humanos do professor alemão Fritzsche: "conhecer e defender seus direitos; respeitar a igualdade de direitos dos outros; e estar tão comprometido quanto possível com a defesa da educação em Direitos Humanos dos outros." Na educação formal, tendo em conta essa concepção, trata-se de pensar ações educativas que contemplem as três dimensões, que devem estar vinculadas, e cumpram o objetivo de educar em direitos humanos.

Em relação à primeira dimensão, é imprescindível o estudo de conteúdos de introdução aos direitos humanos, assim como a contextualização histórica da luta e conquista dos direitos humanos, acordos internacionais e legislações subsequentes, mas também o conhecimento e reflexão sobre os inúmeros casos violações de direitos ocorridos nesse longo percurso a fim de promover a tomada de consciência histórica e impedir o esquecimento de fatos que não devem ser repetidos (CANDAU; SACAVINO, 2013; SILVA; TAVARES, 2013). Tendo o conhecimento histórico e o passado como referência, é fundamental que se busque conhecer melhor o presente, isto é, a situação atual dos direitos humanos no Brasil e, de modo mais específico, da comunidade em que se está inserido, para se seja possível estabelecer relações, realizar uma análise crítica e compreender do que realmente se trata quando se abordam direitos humanos, sua promoção e reconhecimento de casos de violações.

Como parte fundamental da concepção de educação em direitos humanos, o desenvolvimento de estratégias metodológicas participativas e ativas deve permear todo o processo, de modo a estimular os alunos a serem construtores de seus conhecimentos (BRASIL, 2012). Como apontam Candau 
e Sacavino (2013), as estratégias metodológicas precisam estar de acordo com a concepção de educação em direitos humanos e com a concepção de sujeito que se quer formar. Em Pedagogia da autonomia, Paulo Freire (2011, p. 47) apresenta como um dos saberes necessários à prática educativa que "[...] ensinar não é transferir conhecimento, mas criar as possibilidades para a sua própria produção ou a sua construção." Tais possibilidades devem considerar e respeitar os saberes dos educandos, mas precisam contar também com rigor metodológico, pesquisa, criticidade por parte do educador para que seja possível auxiliar os educandos a desenvolverem autonomia no processo de construção e reconstrução dos saberes.

Em relação à construção do conhecimento acima mencionado, uma estratégia pode ser a integração entre ensino e pesquisa, tal como apresentada por Pedro Demo. Ao tomar a pesquisa como princípio científico e educativo, o processo de ensino-aprendizagem se torna cooperativo e o aluno assume um papel de sujeito do processo, o que pode contribuir para a formação de sujeitos emancipados, com autonomia intelectual (DEMO, 2002). A pesquisa deve estar voltada não apenas para o conhecimento já construído historicamente, mas também para a realidade vivida, com a problematização de questões ou situações que fazem parte da vida dos alunos (FREIRE, 2011), de modo ao conhecimento teórico e histórico fornecer sentido às suas experiências, podendo promover mudanças em suas visões de mundo, atitudes e ações.

A dimensão ética da educação em direitos humanos se refere "à formação de atitudes orientadas por valores humanizadores, como a dignidade da pessoa, a liberdade, a igualdade, a justiça, a paz, a reciprocidade entre povos e culturas [...]" (BRASIL, 2012, p. 8). Também devem-se destacar o reconhecimento e valorização das diferenças e das diversidades como princípios fundamentais dessa concepção de educação e que pautam juízos éticos (BRASIL, 2012). Trata-se de propor ações educativas voltadas para a promoção da reflexão ética acerca do ser humano, da sua condição enquanto ser situado em determinado contexto histórico, social, político, cultural, que pode ser ou é diferente de outros e precisa conviver com as diferenças e diversidades. Essa reflexão deve estar voltada para o desenvolvimento da percepção/compreensão do que nos torna iguais aos outros, a dignidade humana, apesar das diferenças.

O filósofo alemão Immanuel Kant, um dos maiores pensadores a se ocupar com o conceito de dignidade da pessoa humana, utilizado na fundamentação dos direitos humanos, já afirmava em Sobre a Pedagogia a necessidade de a educação formal se ocupar também com a formação moral das pessoas (KANT, 2004). Não no sentido de ensinar o aluno a seguir determinados valores morais estabelecidos, mas de ser capaz de refletir e pensar por si mesmo, reconhecendo em si e no outro o direito de humanidade, fundado na 
dignidade humana. Nesse sentido, essa dimensão da educação em direitos humanos visa, fundamentalmente, promover a tomada de consciência da necessidade de reconhecer a igualdade em dignidade e direitos de si mesmo e dos outros, e da sua reafirmação em falas, atitudes, ações e comportamentos. A consciência ética possibilita o reconhecimento de situações e casos de violação da dignidade humana, e habilita o ser humano a posicionar-se, intervir e a agir para restabelecê-la.

A terceira e última dimensão pressupõe as duas anteriores e reside no domínio da ação. Diz respeito à proposição de ações educativas que estimulem os alunos a afirmarem os direitos humanos e a denunciarem violações a fim de compreenderem as implicações dessas questões nas experiências vividas nas relações sociais concretas. Essa dimensão requer o conhecimento da realidade social, política, econômica e cultural local e regional, o pensar as relações sociais estabelecidas e vividas e os padrões que as regem. Trata-se do pensar crítica, ética e politicamente situações-problema, uma experiência vivida por si ou por outro, posicionar-se diante da questão, ser capaz de fazer proposições e agir. Aqui se percebe mais claramente o vínculo entre educação em direitos humanos e formação para o exercício da cidadania ativa, em que o sujeito reconhece a si e o outro enquanto sujeito de direitos e deveres, que compartilham um mundo comum e devem pautar suas ações em valores coletivos.

Tanto o PNEDH quanto as Diretrizes são documentos que se constituem em instrumentos norteadores e fomentadores de ações educativas voltadas para o respeito aos direitos humanos em todos os níveis e modalidades da educação. Na educação básica, as ações educativas, valendo-se de metodologias participativas e ativas, devem possibilitar aos alunos expressarem-se utilizando diferentes linguagens além da escrita acadêmica: "musical, corporal, teatral, literária, plástica, poética, entre outras" (BRASIL, 2012). Além disso, tais ações podem promover a integração de saberes, já que temas relativos aos direitos humanos perpassam, em função do caráter transversal, diversas disciplinas do currículo (BRASIL, 2009, 2012).

No entanto, para se ter êxito no propósito de educar para os direitos humanos, as ações educativas não podem ser reduzidas a atividades isoladas em uma instituição de educação, desempenhadas por um grupo de pessoas. Ações voltadas para a promoção dos direitos humanos e combate às violações devem se fazer presentes no "projeto político-pedagógico, na organização curricular, no modelo de gestão e avaliação, na produção de materiais didático-pedagógicos, quanto na formação inicial e continuada dos/as profissionais da educação." (BRASIL, 2012, p. 7) Dito de outro modo, precisa ser parte integrante da filosofia e da política institucional, e deve haver comprometimento de todos os setores e atores. 
A escola não é apenas o local onde os saberes das mais diversas áreas são produzidos e compartilhados, "[...] a escola é local de estruturação de concepções de mundo e de consciência social, de circulação e de consolidação de valores, de promoção da diversidade cultural, da formação para a cidadania [...]" (BRASIL, 2009, p. 31). A escola se constitui enquanto comunidade e nesse sentido é o espaço privilegiado para ações educativas voltadas para a prática e vivência dos direitos humanos, pois essa comunidade é marcada pela pluralidade de seres humanos, pelas diferenças e diversidades. É nesse espaço que as vivências impõem aos sujeitos experienciar, também, divergências de várias ordens, conflitos, intolerâncias, desigualdades e exclusões. Nessas situações, a escola comprometida com a educação para a cidadania ativa deverá assegurar que as práticas a serem adotadas para as mediações sejam coerentes com os valores e princípios da educação em direitos humanos.

\section{Estudos culturais em educação e algumas de suas contri- buições para os estudos sobre mídias e letramento digital}

Propor uma definição para o campo dos Estudos Culturais (EC) ${ }^{4}$, desde o princípio das pesquisas na área, nunca foi de interesse de seus pesquisadores dado o caráter fluido em que foram concebidos os primeiros estudos atribuídos a ele. Diante da impossibilidade - e da falta de necessidade - de se conceber uma definição para o campo, torna-se mais adequado propor uma discussão acerca de alguns dos percursos mais comumente atribuídos à pesquisa na área. Conforme Costa, Silveira e Sommer (2003, p. 39):

Os Estudos Culturais não constituem um conjunto articulado de ideias e pensamento. Como dizem seus cronistas mais contundentes, eles são e sempre foram um conjunto de formações instáveis e descentradas. Há tantos itinerários de pesquisa e tão diferentes posições teóricas que eles poderiam ser descritos como um tumulto teórico.

Os EC têm, em sua agenda de pesquisa, elementos ligados aos aspectos culturais da sociedade e às mudanças sociais. Costa (2000) propõe que o

4 As discussões que deram origem aos Estudos Culturais começam com a ascensão dos movimentos de democratização na Grã-Bretanha do século XX, em que cada vez mais sujeitos advindos das classes populares obtinham acesso às universidades. A partir do período pós-guerra, Richard Hoggart, Raymond Williams e Edward Thompson alunos representantes das classes operárias -, passam a publicar trabalhos que expressavam as tensões sociais do momento histórico em que viviam e que problematizavam o binarismo entre cultura erudita e culturas populares. Seus trabalhos têm como diferencial a implicação dos autores com o elemento sendo estudado, uma vez que eles não falavam de uma posição externa aos elementos da classe popular sendo estudada, mas de dentro dela e a partir dela. Ademais, eles são os precursores da fundação, em 1964, do Centre for Contemporary Cultural Studies em Birmingham, onde os primeiros estudos na área denominada Estudos Culturais começaram a ser conduzidos. 
ethos contingente dos Estudos Culturais pode ser definido como "saberes que migram de uma disciplina para outra, percorrendo países, grupos, práticas, tradições e que não são capturados pelas cartografias consagradas que têm ordenado a produção do pensamento humano" (p. 13).

Para além de um conceito essencializado e unificado de cultura, Hall (1997) propõe uma definição para o termo. Segundo ele, cultura é o conjunto de significados e práticas sociais que compõem e regulam a maneira de agir dos seres humanos em determinado contexto social. A cultura, nesta perspectiva, permeia cada aspecto da vida cotidiana e é um elemento central da organização social, daí o termo "centralidade da cultura", defendido por Hall. A partir deste entendimento, Bonin et al. (2020), ao discutir a vitalidade das pesquisas em que há o enlace entre Estudos Culturais e Educação, apontam que se deve persistir em propor estudos que problematizem os assuntos que muitas vezes são marginalizados no meio acadêmico, ou até mesmo no âmbito das políticas públicas - tais como questões de gênero, sexualidade, étnico-raciais, identitárias, entre outras -, como forma de subverter verdades e discursos que procuram silenciar e apagar essas discussões, bem como legitimar estes temas como espaços de luta e posicionamento identitário.

Nesse contexto, propor um trabalho de educação em direitos humanos tomando por base as discussões alinhadas ao campo dos Estudos Culturais em Educação abre espaços para ampliar os debates acerca de temas de suma importância que, muitas vezes, ainda não figuram nos currículos escolares como sendo centrais para a formação cidadã. Ainda, a partir dos movimentos de problematização dos conceitos de cultura, linguagem e identidade propostos pelos Estudos Culturais em Educação, é possível ampliar a dimensão dos debates acerca de direitos das minorias, legitimação das culturas e identidades de grupos marginalizados, bem como questionamento das normatividades que buscam silenciar o diferente, por meio da análise de suas construções, tensionamentos e representações.

Nesse sentido, um destaque das pesquisas na articulação dos Estudos Culturais com a Educação, segundo Wortmann, Santos e Ripoll (2019), é a proposta de uma vertente de estudos, compreendida pela expressão "pedagogia cultural". Nela estuda-se o caráter constitutivo e subjetivador das chamadas "áreas pedagógicas", nas quais o poder é organizado e difundido. Nestes estudos, toma-se o caráter discursivo dessas áreas pedagógicas - peças publicitárias, telejornais, videogames, músicas, livros, telenovelas, seriados e mensagens em redes sociais, por exemplo - como elementos que não só informam, mas "educam" seu público, dando lições sobre identidade e constituindo verdades sobre diferentes assuntos.

Tomando por base os estudos de Michel Foucault, a linguagem é in- 
terpretada a partir de seu caráter filosófico, sendo tida como o elemento que possibilita a relação entre o sujeito e o real, mediando a forma como aquele o interpreta e com ele se relaciona. As narrativas, para além de histórias que se contam sobre algo ou alguém, estão permeadas de discursos de múltiplas fontes, contraditórios ou não, que concorrem para construir as verdades acerca dos sujeitos. Entende-se como discurso:

\footnotetext{
Um conjunto de regras anônimas, históricas sempre determinadas no tempo espaço, que definiram em uma dada época, e para uma área social, econômica, geográfica, ou linguística dada, as condições de exercício da função enunciativa. (FOUCAULT, 1999, p. 43).
}

A partir desta perspectiva, Woodward (2011) propõe que os discursos constroem os lugares a partir dos quais os indivíduos podem se posicionar e a partir dos quais podem falar. A autora aponta para o fato de que a mídia, por exemplo, "tem o poder de dizer como as pessoas devem ocupar uma posição-de-sujeito em particular: o adolescente 'esperto', o trabalhador em ascensão ou a mãe sensível" (p. 18). Nesse contexto, trabalhar com educação em direitos humanos, por meio de uma proposta de letramento digital em uma perspectiva dos Estudos Culturais em Educação, é propor uma ação que viabilize ao estudante não apenas compreender e identificar as nuances do preconceito, as violações e os direitos inerentes a cada ser humano, mas promover condições que permitam a ele atuar efetivamente e proficientemente na construção de uma sociedade mais justa e alinhada à defesa e garantia de direitos.

Entrecruzar letramento digital, Estudos Culturais em Educação e Educação em Direitos Humanos em um trabalho escolar é compreender que educar é uma ação de poder. É, também, compreender que esse movimento pode contribuir para uma construção identitária cidadã de um sujeito que terá oportunizadas as condições de não apenas entender como as tecnologias digitais impactam em sua vida em uma posição de sujeito instrumentalizado para consumir mídias, mas de poder posicionar-se como sujeito crítico desse consumo e produtor de mídias, embasando seu trabalho em discursos científicos e que tenham o potencial de problematizar e subverter os discursos que promovem o ódio, a violação de direitos e a banalização da violência.

Cabe neste momento, portanto, discutir de que formas o uso das tecnologias digitais é concebido neste trabalho. Primeiramente, é necessário pontuar que, na história recente da educação mundial, os desafios impostos pela pandemia de COVID-19 cada vez mais impulsionam discursos acerca da necessidade de capacitar professores para o uso das tecnologias. Esse fenômeno muitas vezes é difundido por meio de enunciados "baseados em um tecnicismo educacional, que considera que a introdução de recursos tecnológicos na educação seja algo benéfico e inovador por si mesmo" (SARAIVA; 
TRAVERSINI; LOCKMANN, 2020). Contudo, é importante lembrar que esses discursos acerca do caráter positivo, e até messiânico, das tecnologias na educação não são um fenômeno atual. Segundo Buckingham (2010), desde o início do século XX já circulam discursos que propõem não só articular educação e mídias como uma parceria inata e produtiva, mas até mesmo suplantar a educação pelos objetos midiáticos e tecnológicos. O problema neste discurso reside no fato de que nessas propostas pouca ou nenhuma atenção é dada às necessárias mudanças na metodologia de ensino ou de formação docente para abrir espaço para o uso da tecnologia de forma a construir conhecimento e problematizar o próprio uso das tecnologias na sociedade, vendo-a também como um espaço discursivo em que a linguagem constrói verdades, sentidos e identidades. Comprar equipamentos e softwares que sejam apenas utilizados para reproduzir as práticas tradicionais de ensino, substituindo quadro, giz e livros, não é sinônimo de inovação, mas uma nova roupagem para as mesmas práticas (BUCKINGHAM, 2003, 2007).

É importante destacar que neste artigo não se considera que aprender a usar as tecnologias digitais deva ser abolido ou colocado em segundo plano na escola. Entende-se que saber utilizar as tecnologias digitais é parte fundamental de um mundo que circula entre e nas tecnologias (PISCHETOLA; HEINSFELD, 2017). Contudo, como aponta Buckingham (2010), os debates acerca de seus usos na educação estão por demais polarizados entre os "entusiastas" (para quem a tecnologia em si só é elemento garantidor de sucesso) e os "indiferentes" (que acreditam que a tecnologia pertence ao "mundo exterior" à escola e representa apenas entretenimento e lazer para o aluno). Destarte, é preciso problematizar o uso das tecnologias digitais na educação a partir de estudos e propostas com enfoque na compreensão das formas como elas podem efetivamente ser incluídas nos currículos escolares, bem como na formação de professores com vistas a um uso significativo e que permita ao aluno a compreensão não apenas de como utilizá-las, mas como interpretá-las e como produzi-las.

Segundo Buckingham (2015), uma proposta educacional que vise o letramento digital deve considerar que as mídias digitais não podem ser consideradas como apenas um apoio ou uma ferramenta para o aprendizado. Nesse sentido, é preciso pensar em uma educação sobre as mídias, a qual deve ser vista como um pré-requisito indispensável para a educação com e através das mídias. Ainda segundo o autor, é preciso considerar que na maior parte das experiências de crianças em seus tempos de lazer, os computadores representam muito mais que dispositivos de obtenção de informações: eles comunicam imagens e fantasias, proveem oportunidades para autoexpressão, bem como servem de meio através do qual relações íntimas e pessoais são conduzidas. Essas mídias não podem ser adequadamente compreendidas 
se persistimos em considerá-las apenas como uma questão de máquinas e técnicas, ou como hardware e software.

Dessa forma, se queremos que os alunos usem vídeos, jogos, ou outras mídias digitais no âmbito educacional, é preciso que a escola acolha os conhecimentos prévios dos alunos no uso das tecnologias em momentos de lazer e promova uma análise crítica do funcionamento dessas mídias e tecnologias, levantando o debate acerca das relações entre sujeitos no entorno de seus usos, das representações do mundo construídas por meio delas, bem como das tensões discursivas que nelas podem emergir. O conceito de letramento digital adotado neste artigo origina-se nas discussões propostas por Buckingham (2003). O autor define que o letramento digital pressupõe que o usuário informado de mídias digitais saiba operar dentro dos quatro componentes essenciais do letramento midiático, a saber: representação, língua, produção e audiência.

Quanto à representação, é possível afirmar que as mídias digitais não simplesmente refletem o mundo, mas o representam, oferecendo interpretações e seleções particulares da realidade, a partir da visão de mundo de quem as produziu. Um usuário informado de mídias deve ser capaz de avaliar as motivações dos autores, comparar um texto com outras fontes, identificar se os autores têm autoridade para falar do assunto e os movimentos de silenciamento e protagonismos representados. Quanto à língua, trata-se de domínio do idioma de estudo com fins a não apenas utilizá-lo, mas também entender seus mecanismos de funcionamento e nuances comunicativas e como eles interagem na construção de sentido nas mídias digitais.

Quanto à produção, trata-se de o usuário estar ciente de que todo texto é escrito por alguém tendo em mente um público-alvo e um propósito estabelecido. No contexto da mídia digital, trata-se de entender, por exemplo, dos usos da linguagem feitos por grandes marcas em suas campanhas publicitárias para induzir os sujeitos a uma compra ou a um determinado tipo de comportamento, e como isso se apresenta nos meios tecnológicos. Quanto ao público, o letramento midiático também estimula o sujeito tomar consciência de sua própria posição como público-alvo. Isso significa entender como a mídia é direcionada ao público e como diferentes públicos as usam e respondem a elas.

\section{Relato das ações integradas desenvolvidas em 2020, análises e discussões}

O projeto foi desenvolvido em três etapas, todas adaptadas e desenvolvidas de forma remota em função da pandemia de COVID-19, utilizando-se de recursos como compartilhamento de arquivos de textos e imagens, web-conferências, gravação e compartilhamento de vídeos. Participaram das ações 
todos os discentes das três turmas de primeiros anos dos Cursos Técnicos em Informática e Hospedagem, integrados ao Ensino Médio do IFC/CAS. Alguns discentes tiveram dificuldade de acesso à internet nos primeiros meses de atividades remotas, até a instituição fornecer o auxílio digital. Esses discentes foram atendidos por meio da elaboração e entrega de materiais e atividades impressas, arquivos em pen drive, troca de mensagens com os professores, sempre de acordo com as possibilidades e especificidades apresentadas.

\section{$1^{\text {a }}$ etapa: mapeamento dos conhecimentos prévios}

Primeiramente, foi elaborado e aplicado pelos professores um questionário a fim de diagnosticar o conhecimento e compreensão prévia dos alunos acerca dos direitos humanos e elaborar a partir dos resultados as atividades de estudos e discussões. Como são alunos ingressantes no ensino médio, percebeu-se que nem todos possuíam conhecimentos básicos sobre o tema e muitos relacionaram a existência da Declaração Universal dos Direitos Humanos a uma garantia efetiva desses direitos a todas as pessoas. Foi possível detectar, também, a necessidade de proporcionar o estudo do percurso histórico da luta e conquista de direitos no mundo e no Brasil, dar ênfase para a possibilidade de retrocessos, como mostra a história, e para os avanços e ampliação de direitos nas sociedades democráticas, com a apresentação das gerações ou dimensões dos direitos humanos: civis e políticos, econômicos e sociais, direitos coletivos da humanidade (BOBBIO, 2004; BENEVIDES, 2013). Tal constatação deveu-se ao fato de que a maior parte das respostas mostrou que a compreensão de direitos fundamentais estava voltada para os direitos civis, especialmente a liberdade de expressão, o direito de ir e vir e o direito à propriedade. Também, estava muito presente a concepção de que os direitos humanos seriam algo dado, posto pela legislação existente, desvinculados de toda a contextualização histórica e social.

Outro aspecto importante observado nas respostas dos alunos se refere ao conhecimento de casos de violação de direitos humanos nas suas comunidades. A maior parte respondeu desconhecer casos específicos na comunidade em que vive. A outra parte mencionou casos de violência contra mulheres e discriminação de minorias. Percebeu-se muito presente, ainda, uma noção de "ser portador de direitos humanos" e "ser que sofre violação de direitos humanos" como algo distante de si e da sua comunidade. Ainda, a partir das respostas dos alunos, é possível apontar que a noção de distanciamento com o tema "direitos humanos", seja um resultado do pouco debate proposto acerca do assunto, tanto na sociedade em que vivem, quanto no ambiente escolar. É nesse sentido que surge a necessidade de problematizar 
essa "verdade" (HALL, 1997; FOUCAULT, 1999) recorrente de forma a lançar aos estudantes o questionamento: estariam os debates acerca dos Direitos Humanos distantes da realidade em que vivo? Ou ainda, posso afirmar que não ocorrem violações de direitos na região em que habito?

Dessa forma, mostrou-se fundamental elaborar estratégias e práticas pedagógicas capazes de criar condições à construção do conhecimento sobre a realidade local e regional, ao mesmo tempo em que desenvolvessem a capacidade de estabelecer relações com o conhecimento historicamente construído e a legislação existente acerca do tema, a fim de fazerem uma interpretação da realidade vivida. Para isso, paralelamente aos debates em aula acerca dos temas abordados pelo projeto, optou-se pelo trabalho com mídias digitais, mais especificamente com vídeos. A escolha parte não apenas do desejo de produzir conteúdo de forma não-convencional, mas principalmente por entender que as mídias digitais são hoje gêneros tecnológicos muito presentes no cotidiano, as quais constituem-se em artefatos culturais (BUCKINGHAM, 2015) que atuam como uma pedagogia cultural: mais que representando uma realidade, elas têm o potencial de ensinar e construir verdades acerca de diferentes temas, identidades e contextos (WORTMANN; SANTOS; RIPOLL, 2019).

Para além de formar cidadãos que consomem mídias e tecnologias"de forma consciente", é preciso que a escola tome posse desses gêneros tecnológicos e midiáticos não apenas como objeto de análise, mas também como conteúdo a ser produzido. O letramento digital (BUCKINGHAM, 2003; 2015) passa não apenas pelo desenvolvimento da competência de recepção e interpretação de um gênero midiático, mas também pelo desenvolvimento da competência de produção, provendo ao estudante condições de entender o funcionamento completo do ciclo de produção de textos e conteúdos para as mídias, compreendendo seu funcionamento, suas intencionalidades, seu caráter constituidor de verdades, sua não-parcialidade e, acima de tudo, os aspectos éticos e de cidadania envolvidos nesse processo.

\section{$2^{\text {a }}$ etapa: explorando os Direitos Humanos por meio do ensino e pesquisa}

Na segunda etapa do desenvolvimento do projeto foram realizadas atividades integradas de ensino e pesquisa com os discentes das turmas envolvidas, tendo em consideração os resultados da etapa anterior. Todas as ações dessa etapa visam, também, contemplar a primeira dimensão da educação em direitos humanos - conhecimentos e habilidades, bem como ingressar na segunda dimensão, que diz respeito à reflexão ética-moral (BRASIL, 2009), conforme exposto anteriormente. Os estudos e discussões sobre direitos hu- 
manos foram realizados por meio de atividades integradas entre disciplinas e abordagem de temas específicos por alguns professores, sempre de acordo com a sua área de interesse de pesquisa.

Foram realizados estudos e discussões de introdução aos direitos humanos, acordos e legislações existentes, sua contextualização histórica no mundo e no Brasil, com o objetivo de contribuir na compreensão do tema e sua trajetória histórica de uma perspectiva crítica e científica, como orientam o PNEDH e Diretrizes (BRASIL, 2009; 2012) com vistas à formação de sujeitos de direitos. Também foram apresentados pelos professores e discutidos casos de violações de direitos humanos ocorridos no Brasil, a fim de desenvolver a capacidade de reconhecer uma situação de negação de direitos e estabelecer relações entre a legislação vigente e a realidade vivida. Mostrou-se interessante a mediação dos debates quando a desconstrução do senso comum de que "todos têm os mesmos direitos" era fomentada pela fala de alunos, que justamente ocupam o lugar daqueles que veem diariamente seus direitos serem negados e violados (mulheres e pessoas que pertencem a grupos que sofrem discriminação). Assim, após leituras selecionadas, visualização de obras audiovisuais e debates, criou-se um espaço de compreensão e desenvolvimento da capacidade de argumentação sobre esses temas.

Nesta etapa também foi realizada pelos alunos uma atividade de pesquisa, encaminhada de forma integrada entre todas as disciplinas envolvidas, constando de leitura de bibliografia específica sobre os temas e pesquisa de casos documentados de violações de direitos ocorridos nos municípios em que residem os alunos (municípios da região do extremo sul de Santa Catarina e litoral norte do Rio Grande do Sul). As pesquisas de casos de violações de direitos foram realizadas em sites jornalísticos, por meio eletrônico, ou jornais impressos. Também foram autorizados e acolhidos pelo grupo docente três casos de relatos de familiares coletados por alunos.

Os resultados das pesquisas foram apresentados pelos alunos de forma textual, com análise crítica dos casos à luz do referencial teórico, caracterizando-se como uma atividade introdutória à escrita acadêmica. A estratégia metodológica dessa atividade, compreendida como participativa e ativa (FREIRE, 2011), foi adotada para estimular os alunos a serem construtores de conhecimentos (BRASIL, 2012; CANDAU; SACAVINO, 2013). Ela se pauta, também, na concepção de ensinar pela pesquisa (DEMO, 2002), colocando o aluno como sujeito do processo de ensino-aprendizagem, já que os professores desempenham o papel de orientadores das pesquisas. No início da atividade os alunos são orientados a buscar um caso que se relacione com um dos temas que desperte mais o seu interesse de pesquisa e estudo, a fim de facilitar e tornar mais prazeroso o processo de análise e produção textual. Os professores 
dão suporte, enquanto os alunos são os protagonistas de todo o processo. As pesquisas foram realizadas em equipe, totalizando 17 trabalhos de pesquisa, que abordaram as seguintes temáticas, de acordo com os casos de violações de direitos apresentados: - violência contra a mulher (violência psicológica, abuso e violência sexual, agressão física, feminicídio) (5 trabalhos); - discriminação de pessoas com transtornos mentais ( 2 trabalhos); - negligência, abuso e violência contra menores ( 3 trabalhos); - racismo ( 2 trabalhos); - homofobia e transfobia; - (3 trabalhos); - trabalho análogo à escravidão (2) trabalhos.

As apresentações foram interessantes, pois os alunos trouxeram casos recentemente ocorridos em suas comunidades, mostrando que compreenderam um aspecto fundamental no que tange a discussão sobre direitos humanos: trata-se de algo que diz respeito a todos, na medida em que quando uma violação de direitos não nos afeta diretamente, afeta quem está muito próximo de nós. A partir dos resultados dessa atividade, percebeu-se como pode ser significativo o estudo de temas que extrapolam o currículo escolar quando se proporciona ao sujeito estabelecer relações com a realidade local (BONIN et al, 2020). É justamente essa relação que contribui na interpretação de si enquanto sujeito de direitos e no reconhecimento dos demais também enquanto tais.

\section{$3^{a}$ etapa: Produção de mídias digitais para promoção dos Direitos Humanos}

A terceira etapa, realizada no terceiro trimestre, foi a de produção de mídias digitais no formato de vídeos curtos pelos alunos. Esta etapa teve de ser adaptada em relação aos anos anteriores, pois costumava-se ofertar oficinas de roteiro, fotografia, direção, interpretação e edição para preparar e dar suporte aos alunos na produção, o que esse ano não foi possível pois os alunos não disporiam dos equipamentos da instituição como forma de apoio a suas produções. Além disso, também se apresentou a impossibilidade de realizar presencialmente as gravações devido à pandemia. Em razão disso, foi solicitado aos alunos que produzissem, individualmente, em dupla ou em trio (sem encontros presenciais), utilizando a câmera do celular, vídeos de 45 segundos a 2 minutos, em formato similar aos vídeos informativos e campanhas promocionais publicitárias, abordando de forma crítica um dos temas relativos aos direitos humanos estudados e pesquisados nas etapas anteriores. $O$ objetivo do vídeo produzido seria levar o espectador à reflexão sobre o tema em questão, visando a problematização, a discussão, a promoção da tolerância e o respeito às diferenças e à diversidade.

Essa etapa do trabalho foi organizada com base no conceito de letramento digital proposto por Buckingham (2003), sendo balizada nos quatro 
componentes essenciais do letramento midiático: representação, língua, produção e audiência. Nesse contexto, promoveu-se um espaço de discussão com os alunos no sentido de analisar o aspecto da representação, construindo o conceito de que as mídias digitais não apenas refletem o mundo, mas oferecem interpretações e seleções particulares da realidade, a partir da visão de mundo de quem as produziu. Agora, na posição de autores, eles precisavam avaliar suas motivações e identificar se eles mesmos tinham autoridade para falar do tema proposto para a produção dos vídeos.

Ainda segundo o autor, quanto à língua, os alunos foram instruídos no sentido de avaliar se a linguagem e os jogos de palavras propostos produziam a mensagem esperada pelo grupo no sentido da defesa dos direitos da população representada nos vídeos, de forma a fazer uma produção justa e coerente com o objetivo traçado pelo projeto. Quanto ao público, debateu-se com os alunos a necessidade de se perceber como sujeito em um ciclo de produção midiática. Basicamente, na posição de autores, os alunos precisavam entender como a mídia é direcionada ao público e como os diferentes públicos as usam e respondem a elas, inclusive ao trabalho deles.

A produção do roteiro com todos os elementos constituintes (texto, imagens, voz, trilha sonora) do vídeo precedeu a fase de produção e deveria passar pela aprovação do professor orientador. Para a produção do vídeo poderiam ser utilizadas diversas linguagens artísticas, se adequando às habilidades, interesses e criatividade dos alunos, e a mensagem que desejassem passar. Os professores deram suporte para a utilização legal de imagens e trilha sonora, assim como para o uso de aplicativos de edição de vídeos. $\mathrm{Na}$ maior parte dos vídeos, os alunos aparecem como protagonistas nas imagens produzidas, mostrando o engajamento no trabalho. Nessa etapa do projeto procurou-se contemplar a segunda e a terceira dimensões da concepção de educação em direitos humanos: - afirmação de valores, atitudes e comportamentos - reflexão ética-moral; - ação ética-política; - promover a ação e engajamento na defesa dos direitos humanos (BRASIL, 2009, 2012).

Foram produzidos 59 vídeos, que abordam diversos temas relativos aos direitos humanos e apresentam no final um canal para buscar ajuda ou fazer uma denúncia em casos de violações. Os vídeos produzidos apresentam as seguintes temáticas: - violência contra a mulher (violência psicológica, abuso e violência sexual, agressão física, feminicídio) (19 vídeos); - discriminação de pessoas com transtornos mentais - 9 vídeos; negligência, abuso e violência contra menores (4 vídeos); - racismo (8 vídeos); xenofobia; (1 vídeo); homofobia e transfobia (6 vídeos); - trabalho análogo à escravidão (5 vídeos); - trabalho infantil (1 vídeo); - intolerância religiosa (2 vídeos); - discriminação de pessoa com deficiência (1 vídeo); - direitos humanos (1 vídeo); - isolamen- 
to social na pandemia de Covid-19 (11 vídeos).

Alguns vídeos abordaram mais de um tema. As melhores produções receberam dos professores do projeto indicação para premiação, de acordo com categorias distintas, em evento que ocorrerá em 2021, após o retorno às atividades presenciais. Os vídeos produzidos ficarão disponíveis no acervo do IFC/CAS para ser publicado nas redes sociais do projeto e utilizado como material de apoio para discussões a respeito dos direitos humanos.

\section{Considerações finais}

Nas produções de vídeos realizadas pelos alunos, produto final do processo, pode-se perceber a presença de aspectos da parte de ensino e pesquisa, já que mostraram preocupação em representar da melhor maneira possível o grupo de pessoas implicado. Compreende-se que a proposta cumpriu seu objetivo geral, pois possibilitou a aprendizagem por meio da pesquisa e da produção de mídias digitais, ao mesmo tempo em que promoveu a reflexão, indo para além das questões curriculares, investindo na formação da consciência ética, na análise crítica da convivência humana e no letramento digital com fins à formação cidadã.

A proposta pedagógica deste projeto contemplou as três dimensões da Educação em Direitos Humanos, bem como promoveu o protagonismo dos alunos na pesquisa e análise de casos de violação na região em que vivem. Além disso, possibilitou espaço de debate para uma reinterpretação do papel das mídias digitais no cotidiano, proporcionando aos alunos uma ampliação de seu escopo de uso das tecnologias, passando de consumidores a produtores de conteúdo com o entendimento de como funciona o ciclo da produção e recepção midiática.

Para além de um resultado positivo entre os alunos, foi possível também compartilhar experiências em trabalho de equipe, o qual envolveu docentes de distintas áreas do conhecimento. Cada vez mais torna-se importante transgredir as fronteiras disciplinares, tornando o trabalho da escola uma ação conjunta e que integra os saberes de diferentes áreas para a produção de uma experiência educacional mais conectada com o contexto em que estamos inseridos e que proporcione um olhar para dentro e para fora dos muros da escola. Estabelecer relações entre os conteúdos escolares, temas transversais e contexto social da comunidade é de suma importância para superarmos dificuldades históricas em contextualizar o aprendizado.

Apesar dos aspectos positivos deste projeto, foi possível mapear algumas dificuldades que não apenas dizem respeito ao âmbito do projeto, mas apontam para um contexto mais amplo da educação brasileira e da formação de profes- 
sores. Ainda são poucos os docentes que tiveram em sua formação inicial discussões mais centradas na Educação em Direitos Humanos, suas metodologias e suas possibilidades. No que diz respeito às ações do projeto apresentado neste trabalho, antes mesmo de debater com os alunos determinados temas, foi preciso compartilhar com o grupo docente que integra o projeto interdisciplinar algumas reflexões sobre temas nele abordados e sua importância como elementos de formação cidadã no contexto escolar e da sociedade em geral.

É preciso destacar, também, que existe uma diferença entre o ambiente escolar estar aberto ao acolhimento do diferente e efetivamente promover um ambiente de educação em Direitos Humanos. Ainda que o trabalho interdisciplinar envolva boa parte do corpo docente da instituição, é preciso que toda a comunidade escolar esteja ciente do que são violações de direitos e auxiliem na construção de uma cultura de respeito e empatia, uma vez que as violações abordadas no âmbito do projeto também podem ocorrer com membros da comunidade. Nesse sentido, percebeu-se a necessidade de, em futuras edições do projeto, promover ações que abranjam todos os níveis da instituição.

Paralelamente a essa interpretação, também foi possível mapear, nas interações em nossas reuniões de organização, as dificuldades e carências no que diz respeito à formação docente para o uso das tecnologias em sala de aula. Além disso, identificaram-se carências e dificuldades semelhantes em parte do grupo discente atendida pelo projeto. Conforme discutido anteriormente, não basta utilizar hardwares e softwares como meros instrumentos para promover um letramento digital (BUCKINGHAM, 2003). Esses elementos são importantes, mas não centrais. Formar sujeitos proficientes no uso das tecnologias requer um estudo dos jogos de poder, tensões discursivas, características e ciclo de produção e consumo dos gêneros midiáticos e das tecnologias utilizadas. É preciso ver a tecnologia aplicada à educação não apenas como uma ferramenta de apoio, ou mesmo de "edutenimento", mas como artefatos culturais onde se dão negociações identitárias, práticas discursivas, construção de verdades e, também, aprendizado (BUCKINGHAM, 2015).

Nesse sentido, é preciso reinterpretar a posição do professor e a posição do aluno no processo de construção do conhecimento mediado por tecnologias digitais, abrindo espaço para um maior protagonismo do estudante no mapeamento e reconhecimento das características e tensões dos usos das tecnologias, bem como posicionando o professor como mediador da construção desses saberes. Trabalhar nas fronteiras do novo pode ser uma experiência complexa para alguns docentes mais acostumados com uma metodologia convencional, mas certamente traz resultados. 


\section{Referências}

BRASIL. Constituição (1988). Constituição da República Federativa do Brasil. 37. ed. São Paulo: Atlas, 2014.

BRASIL. Lei no 9.394, de 20 de dezembro de 1996. Lei de Diretrizes e Bases da Educação Nacional. Brasília, DF: 1996. Disponível em: http://www.planalto. gov.br/ccivil_03/leis/19394.htm. Acesso em: 13 mai. 2020.

BRASIL. Plano Nacional de Educação em Direitos Humanos. 5. tir. atual. Brasília: MEC/SEDH, 2009. Disponível em: http://portal.mec.gov.br/docman/2191plano-nacional-pdf/file. Acesso em: 13 mai. 2020.

BRASIL. Ministério da Educação. Secretaria de Educação Fundamental. Parâmetros Curriculares Nacionais: apresentação dos temas transversais, ética. Brasília, DF: MEC/SEF, 1997. Disponível em: http://portal.mec.gov.br/seb/ arquivos/pdf/ttransversais.pdf. Acesso em: 30 abr. 2020.

BRASIL. Ministério da Educação/Conselho Nacional de Educação. Diretrizes Nacionais para a Educação em Direitos Humanos. Brasília: MEC/CNE, 2012. Disponível em: http://portal.mec.gov.br/dmdocuments/rcp001_12.pdf. Acesso em: 30 abr. 2020.

BENEVIDES, Maria V. de M. Cidadania e democracia. Lua Nova, São Paulo, n. 33, p.5-16, 1994. Disponível em: https://www.scielo.br/scielo.php?script=sci_ arttext\&pid=S0102-64451994000200002. Acesso em: 12 ago. 2020.

BENEVIDES, Maria V. de M. Cidadania e direitos humanos. IEA. USP. 2013. Disponível em: http://www.iea.usp.br/publicacoes/textos. Acesso em: 20 ago. 2020.

BOBBIO, Norberto. A era dos direitos. Trad. de Carlos Nelson Coutinho; apresentação de Celso Lafer. Rio de Janeiro: Elsevier, 2004.

BONIN, lara Tatiana et al. Por que estudos culturais? Educação \& Realidade [online], Porto Alegre, v. 45, n. 2, p. 1-22, jun., 2020. Disponível em: https://doi. org/10.1590/2175-6236100356. Acesso em: 30 jul. 2020.

BUCKINGHAM, David. Media education: literacy, learning and contemporary culture. Cambridge: Polity Press, 2003. 
BUCKINGHAM, David. Beyond technology: children's learning in the age of digital culture. Cambridge, Polity Press, 2007.

BUCKINGHAM, David. Cultura digital, educação midiática e o lugar da escolarização. Educação e Realidade. Porto Alegre, v. 35, n. 3, p. 37-58, set./ dez., 2010. Disponível em: https://seer.ufrgs.br/educacaoerealidade/article/ view/13077/10270 Acesso em: 25 jul 2020.

BUCKINGHAM, David. Defining digital literacy: what do young people need to know about digital media? Nordic Journal of Digital Literacy, Oslo (Noruega), v. 4, p. 21-34, nov. 2015. Disponível em:https://www.idunn.no/dk/2006/04/ defining_digital_literacy_-_what_do_young_people_need_to_know_ about_digital?languageld=2 Acesso em: 1 jul 2020

CANDAU, Vera M. F.; SACAVINO, Susana B. Educação em direitos humanos e formação de educadores. Educação, Porto Alegre, v. 36, n. 1, 2013. Disponível em: $\quad$ https://revistaseletronicas.pucrs.br/ojs/index.php/faced/article/ view/12319/8741. Acesso em: 20 mar. 2020.

COSTA, Marisa V.; SILVEIRA, Rosa H.; SOMMER, Luis H. Estudos culturais, educação e pedagogia. Revista Brasileira de Educação, Rio de Janeiro, n. 23, p. 36-61, mai./jun./jul./ago. 2003. Disponível em: https://www.scielo.br/j/ rbedu/a/FPTpjZfwdKbY7qWXgBpLNCN/?format=pdf\&lang=pt Acesso em: 23 ago 2020.

COSTA, Marisa V.; SILVEIRA, Rosa H.; SOMMER, Luis H. Estudos Culturais para além das fronteiras disciplinares. In: COSTA, Marisa V. Estudos culturais em educação. Mídia, arquitetura, brinquedo, biologia, literatura, cinema. Porto Alegre: Ed. da UFRGS, 2000. p. 13-35.

DEMO, Pedro. Pesquisa: princípio científico e educativo. 9a ed. São Paulo: Cortez, 2002.

FOUCAULT, Michel. Microfísica do poder. Trad. Machado, R., 14a ed. Rio de Janeiro: Graal. 1999.

FREIRE, Paulo. Pedagogia da autonomia: saberes necessários à prática educativa. São Paulo: Paz e terra, 2011.

HALL, Stuart. A centralidade da cultura: notas sobre as revoluções centrais 
do nosso tempo. Educação e Realidade, Porto Alegre, v. 22, n. 2, jul./dez., p.15-46, 1997. Tradução: Ricardo Uebel, Maria Isabel Bujes e Marisa Vorraber Costa. Disponível em: https://seer.ufrgs.br/educacaoerealidade/article/ view/71361/40514 Acesso em: 25 jul 2020

KANT, Immanuel. Sobre a Pedagogia. Trad. de Francisco Cock Fontanella. $4^{a}$ ed., Piracicaba: UNIMEP, 2004.

ONU. Declaração Universal dos Direitos Humanos. França, 1948. Disponível em: https://nacoesunidas.org/direitoshumanos/declaracao. Acesso em: 20 jul. 2020.

PISCHETOLA, M; HEINSFELD, B. Tecnologias, estilo motivacional do professor e democracia em sala de aula. In: IX Seminário Internacional. As Redes Educativas e as Tecnologias, UERJ, Rio de Janeiro, 5 a 8 de junho de 2017. Disponível em: http://www.seminarioredes.com.br/ixredes/adm/trabalhos/diagramados/ TR1047.pdf Acesso em: 25 jul 2020

SARAIVA, Karla; TRAVERSINI, Clarice; LOCKMANN, Kamila. A Educação em Tempos de Covid-19: ensino remoto e exaustão docente. Práxis Educativa. Ponta Grossa, v. 15, p. 1-24, ago. 2020. Disponível em: https://revistas2.uepg. br/index.php/praxiseducativa/article/view/16289/209209213529 Acesso em: 15 set 2020

SILVA, Aida Maria Monteiro.;TAVARES, Celma. Educação em direitos humanos no Brasil: contexto, processo de desenvolvimento, conquistas e limites. Educação, Porto Alegre, v. 36, n. 1, 2013. Disponível em: https://revistaseletronicas.pucrs. br/ojs/index.php/faced/article/view/12315. Acesso em: 20 mar.2020.

WOODWARD, K. Identidade e diferença: uma introdução teórica e conceitual. In: SILVA, T, T. da. (org.) Identidade e diferença: a perspectiva dos estudos culturais. 10. ed. Petrópolis, RJ: Vozes, 2011, p.7-72.

WORTMANN, Maria Lúcia C.; SANTOS, Luís Henrique S. dos; RIPOLL, Daniela. Apontamentos sobre os Estudos Culturais no Brasil. Educação \& Realidade [online], Porto Alegre, v. 44, n. 4, Nov. 2019. Disponível em: https://doi. org/10.1590/2175-623689212. Acesso em: 5 jun. 2021. 